\title{
Analisis Efektivitas SOP Pelaksanaan Penyimpanan Berkas Rekam Medis Di Puskesmas Lawang
}

\author{
Ina Suhartina ${ }^{1}$, Tri Murni, $\mathbf{M}^{2}$, Riska Diana, $\mathbf{P}^{3}$ \\ ${ }^{1,2,3}$ Sekolah Tinggi Ilmu Administrasi Malang \\ E-mail: ${ }^{1}$ inasuhartina57@gmail.com
}

\begin{abstract}
The service of medical record documents, is required to provide files quickly and accurately. Based on the results of observations during street vendors at Lawang Health Center, the authors found that the implementation of medical record file storage in Lawang Health Center was not in accordance with (Standard Operational Procedure). The study was conducted to analyze the effectiveness of medical record file storage SOPs at Lawang Health Center. The type of research used is qualitative research. The phenomenology approach is used in research because it focuses on describing what is common / common to all participants when they experience a phenomenon. Data collected are interview data and documentation. There were 4 officers in the medical record room including 1 medical record graduate, 1 midwifery graduate, and 2 high school graduates who already had basic skills in managing medical record files. At the Lawang Community Health Center there was a policy but there was still no information about the obligations of the officers in carrying out the storage of medical records. The results showed that $30 \%$ had not implemented the SOP effectively so that it caused missing and difficult files to track it. In addition, the flow of medical record documents is embedded and written. The medical record room is $\pm 2 m \times 2.5 \mathrm{~m}$ with a medical record file of 29200 files. This results in the process of searching the medical record file to be slow and ineffective.
\end{abstract}

Keywords: Medical Record File, SOP, Storage, Puskesmas.

\begin{abstract}
Abstrak
Pelayanan dokumen rekam medis, dituntut menyediakan berkas secara cepat dan tepat. Berdasarkan hasil pengamatan selama PKL di Puskesmas Lawang, penulis menemukan bahwa pelaksanaan penyimpanan berkas rekam medis di Puskesmas Lawang belum sesuai dengan (Standart Operational Procedure). Penelitian dilakukan untuk menganalisis efektivitas SOP penyimpanan berkas rekam medis di Puskesmas Lawang. Jenis penelitian yang digunakan adalah penelitian kualitatif. Pendekatan fenomenologi digunakan dalam penelitian karena berfokus untuk mendeskripsikan apa yang sama/umum dari semua partisipan ketika mereka mengalami fenomena. Data yang dikumpulkan adalah data hasil wawancara dan dokumentasi. Terdapat 4 petugas diruang rekam medis diantaranya adalah 1 orang lulusan Rekam medis, 1 orang lulusan kebidanan, dan 2 orang lulusan SMA yang sudah memiliki ketrampilan dasar mengenai pengelolaan berkas rekam medis. Di Puskesmas Lawang sudah terdapat kebijakan akan tetapi masih belum adanya keterangan tentang kewajiban petugas dalam pelaksanaan penyimpanan berkas rekam medis. Hasil penelitian menunjukan $30 \%$ belum melaksanakan SOP dengan efektif sehingga menyebabkan terdapat berkas hilang dan sulit dalam melacaknya. Selain itu alur dokumen rekam medis secara tertempel dan tertulis. Ruang rekam medis berukuran $\pm 2 \mathrm{~m}$ x 2,5 m dengan berkas rekam medis sebanyak 29200 berkas. Hal ini mengakibatkan proses pencarian berkas rekam medis menjadi lambat dan tidak efektif.
\end{abstract}

Kata kunci: Berkas Rekam Medis, SOP, Penyimpanan, Puskesmas

\section{Pendahuluan}

Pusat Kesehatan Masyarakat (Puskesmas) adalah organisasi fungsional yang menyelenggarakan upaya kesehatan yang bersifat menyeluruh, terpadu, merata dapat diterima dan terjangkau oleh masyarakat dengan peran serta aktif masyarakat dan menggunakan hasil ilmu pengetahuan dan masyarakat. Puskesmas dapat memberikan pelayanan rawat inap dan rawat jalan (Ismainar, 2015).

Rekam medis adalah berkas yang berisi catatan dan dokumen antara lain identitas pasien, hasil pemeriksaan, pengobatan yang telah diberikan, serta 
tindakan dan pelayanan lain yang telah diberikan kepada pasien (Butt, 2010). Kegunaan rekam medis menurut Murni, dkk (2018) adalah sebagai dasar pemeliharaan kesehatan dan pengobatan pasien, sebagai bahan pembuktian dalam perkara hukum, bahan untuk kepentingan penelitian, sebagai dasar pembayaran biaya pelayanan kesehatan dan sebagai bahan untuk menyiapkan statistik kesehatan. rekam medis terbagi atas beberapa bagian yaitu (rawat inap, dan rawat jalan), assembling, koding, filling, dan analising /reporting.

Salah satu bagian yang menunjang kelancaran pelayanan di bidang rekam medis adalah bagian filing yang berfungsi sebagai tempat penyimpanan rekam medis. Menurut Budiharjo (2014) "sistem penyimpanan adalah sistem yang digunakan pada penyimpan dokumen agar kemudahan kerja penyimpanan dapat diciptakan dan penemuan dokumen yang sudah disimpan dapat dilakukan dengan cepat bilamana dokumen tersebut sewaktuwaktu dibutuhkan". Hal tersebut harus disesuaikan dengan Standar Operasional Prosedur (SOP) yang telah ditetapkan oleh puskesmas sebagai acuan dalam pelaksanaan tugas yang harus dipatuhi oleh semua petugas pada setiap unit.

Setiap perusahaan bagaimanapun bentuk dan apapun jenisnya, membutuhkan sebuah panduan untuk menjalankan tugas dan fungsi setiap elemen atau unit perusahaan. Standar Prosedur Operasional (SPO) adalah sistem yang disusun untuk memudahkan, merapihkan dan menertibkan pekerjaan. Sistem ini berisi urutan proses melakukan pekerjaan dari awal sampai akhir. Sailendra, (2015) menyatakan "Standard Operating Procedure (SOP) merupakan panduan yang digunakan untuk memastikan kegiatan operasional organisasi atau perusahaan berjalan dengan lancar". Lebih lanjut Seilendra (2015) menjelaskan bahwa Standard Operating Procedure (SOP) adalah satu set instruksi tertulis yang digunakan untuk kegiatan rutin atau aktivitas yang berulang kali dilakukan oleh sebuah organisasi. Sedangkan Budihardjo (2014) menyatakan :"Standard Operating Procedure (SOP) adalah suatu perangkat lunak pengatur, yang mengatur tahapan suatu proses kerja atau prosedur kerja tertentu."

Berdasarkan survey awal pada bulan April hingga Mei Tahun 2018 di Puskesmas Lawang terlihat pelayanan Berkas Rekam Medis (DRM) lebih dari ketetapan waktu 5 menit pada Standar Operasional Prosdur (SOP) pengukuran sasaran mutu waktu tunggu proses pendaftaran sampai ke poliklinik dikarenakan sulitnya pengambilan kembali Berkas Rekam Medis saat pasien akan berobat. Selain itu di tempat filling ditemukan bahwa $\pm 15 \%$ dokumen rekam medis tidak dirak file karena belum dikembalikan setelah digunakan.

Hal ini dikarenakan tidak digunakannya tracer sebagai pengganti berkas rekam medis keluar sehingga dapat mengalami kesulitan dalam mencari dan mengembalikan berkas rekam medis, sering ditemukannya dokumen rekam medis yang hilang atau salah peletakannya dan tidak digunakannya buku ekspedisi dalam pencatatan dokumen rekam medis yang keluar dan masuk ruang filling juga menjadi faktor lebihnya ketepatan waktu 5 menit pada SOP. Jika hal tersebut terus-menerus didiamkan tanpa perbaikan maka akan berdampak pada berkurangnya jumlah kunjungan poliklinik puskesmas dan kepercayaan pasien terhadap pelayanan hilang sehingga membuat kerugian pada puskesmas.

Berangkat dari masalah yang telah dipaparkan di Puskesmas Lawang, tujuan penelitian ini adalah mengetahui pelaksanan penyimpanan berkas rekam medis berdasarkan Standart Operasional Prosedur (SOP) di Puskesmas Lawang dan mengetahui alur prosedur pelayanan berkas rekam medis di Puskesmas Lawang.

\section{Metode}

Dalam pelaksanaan penelitian harus menggunakan metode yang tepat agar sesuai dengan tujuan penelitian. Pada penelitian ini peneliti menggunakan penelitian kualitatif. Menurut Denzin \& Lincoln (2011) Penelitian kualitatif merupakan penelitian yang melibatkan suatu pendekatan penafsiran yang naturalistik. Hal ini berarti bahwa penelitian kualitatif mempelajari benda-benda dilingkungan alamiah, berusaha untuk menafsirkan fenomena dari sudut pandang makna-makna yang diberikan oleh masyarakat (Cresswell, 2015).

Adapun pendekatan yang digunakan dalam penelitian adalah fenomenologi karena penelitian berfokus untuk mendiskripsikan apa yang sama/umum dari semua partisipan ketika mereka mengalami fenomena. Tujuan utama dari fenomenologi adalah untuk mereduksi pengalaman individu pada fenomena menjadi diskripsi tentang esensi atau intisari (Cresswell, 2015). Dalam proses ini peneliti mendiskripsikan gejala sebagaimana gejala itu menampakkan dirinya pada pengamatan, maksudnya 
peneliti menggali data yang dimunculkan lewat pengalaman-pengalaman subjek.

Menggunakan metode kualitatif dirasa sangat sesuai karena mampu menjawab tujuan penelitian yaitu mengetahui penyimpanan berkas rekam medis sesuai dengan SOP di Puskesmas Lawang dan mengetahui alur prosedur pelayanan rekam medis. Tujuan dari penelitian kualitatif yakni mencakup informasi tentang fenomena utama yang dieksplorasi dalam penelitian, partisipan penelitian dan lokasi penelitian (Cresswell, 2015). Melalui tujuan penelitian kualitatif, peneliti melakukan penelitian secara partisipan dengan mengumpulkan data melalui pengamatan, wawancara dan dokumentasi.

Lokasi penelitaia dilakukan di Puskesmas Lawang di jalan Sumber Waras Kelurahan Kalirejo Kecamatan Lawang pada September 2018. Dasar pertimbangan pengambilan penelitian di puskemas ini adalah karena sudah melakukan survei dan pengambilan data pada saat pelaksanaan praktek kerja lapangan di Puskesmas Lawang. Lokasi yang digunakan untuk pengambilan data adalah Unit Rekam Medis Rawat Jalan khususnya dibagian Sistem Penyimpanan Berkas Rekam Medis (Filling).

Menurut Cresswell (2015), fokus penelitian ini dimaksudkan untuk membatasi penelitian guna memilih mana data yang relevan dan yang tidak relevan, agar tidak dimasukkan ke dalam sejumlah data yang sedang dikumpulkan, walaupun data itu menarik. Perumusan fokus masalah dalam penelitian ini bersifat tentatif, artinya penyempurna rumusan masalah masih tetap dilakukan sewaktu penelitian sudah berada dilapangan. Berdasarkan rumusan masalah yang ada maka dapat diuraikan kepada fokus penelitian antara lain:

1. Persyaratan/Kualifikasi Petugas Rekam Medis di Puskesmas Lawang.

2. Kebijakan Penyimpanan Berkas Rekam Medis di Puskesmas Lawang.

3. Alur Berkas Rekam Medis di Puskesmas Lawang.

4. Sistem Penyimpanan Berkas Rekam Medis di Puskesmas Lawang.

5. Sistem Pengambilan dan Pengembalian Berkas rekam medis di Puskesmas Lawang.

6. Ruang Penyimpanan Berkas Rekam Medis dan Letak Arsip di Puskesmas Lawang.

7. Jarak Pendistribusian Berkas Rekam Medis ke poli di Puskesmas Lawang.
Data dikumpulkan dengan mengobservasi perilaku petugas rekam medis, wawancara dan dokumentasi. Kegiatan Observasi ini dilakukan dengan cara mengamati perilaku, kegiatan yang dilakukan rekam medis Puskesmas Lawang untuk mendapatkan data mengenai pelaksanaan penyimpanan berkas rekam medis, alur berkas rekam medis, ukuran ruangan filling, rak filling, dan jarak tempuh rekam medis dalam mendistribusikan berkas rekam medis ke poli tujuan, letak arsip disimpan. Setelah data dikumpulkan, data tersebut akan dianalisis dan disimpulkan untuk dijadikan hasil penelitian.

\section{Hasil}

\section{Kualifikasi Petugas Rekam Medis}

Kualifikasi petugas rekam medis di Puskesmas Lawang diketahui terdapat 4 petugas rekam medis pada tabel 1 .

Tabel 1 Kualifikasi Petugas Rekam Medis Puskesmas Lawang

\begin{tabular}{|c|c|c|c|c|c|}
\hline \multirow[t]{3}{*}{ No } & \multirow[t]{3}{*}{ Jabatan } & \multicolumn{3}{|c|}{ Pendidikan } & \multirow[t]{3}{*}{ Total } \\
\hline & & SMA & D3 & D3 & \\
\hline & & & RMIK & Lain & \\
\hline 1 & $\begin{array}{c}\text { Koordina- } \\
\text { tor Rekam } \\
\text { Medis }\end{array}$ & & & 1 & 1 \\
\hline 2 & Pelaksana & 2 & 1 & & 3 \\
\hline \multicolumn{5}{|c|}{ Total Keseluruhan } & 4 \\
\hline
\end{tabular}

Lulusan SMA sebanyak 2 orang, Lulusan D3 RMIK sebanyak 1 orang dan Koordinator Rekam medis lulusan D3 Kebidanan sebanyak 1 orang. Dimana petugas yang berada di Pendaftaran sebanyak 3 orang. Filling sebanyak 1 orang, dan 1 petugas pendaftaran merangkap membantu petugas filling. Semua penyimpanan berkas rekam medis dilakukan oleh petugas rekam medis.

Berdasarkan hasil identifikasi dapat diketahui kualifikasi tenaga pelaksana yang bekerja di sana memiliki standart pendidikan minimal SMA dan maximal adalah D3. Akan tetapi sudah dilakukan pelatihan tentang rekam medis dan managemen rekam medis dasar. Berdasarkan hasil wawancara dijelaskan bahwa dengan rata-rata pasien 120 perhari 
tenaga bagian filling kurang dikarenakan petugas merangkap pekerjaan yaitu penyiapan berkas, assembling, cek data pasien tidak membawa kartu berobat dan mendistribusikan berkas.

\section{SOP Penyimpanan rekam medis}

Puskesmas Lawang memiliki SOP khusus untuk penyimpanan berkas rekam medis. Sebagai berikut:

a. Petugas mengambil dokumen rekam medis dari petugas poli

b. Petugas mencatat dikumen rekam medis yang keluar pada lembar ekspedisi rekam medis

c. Petugas mengembalikan rekam medis sesuai dengan nomor urut indexnya dan mengambil tracer ke dalam rak penyimpanan rekam medis masing-masing

d. Petugas mengurutkan rekam medis sesuai dengan nomor indexnya

e. Petugas merapikan susunan rekam medis agar tetap rapi dan benar

Hasil pengamatan yang dilakukan terhadap petugas rekam medis Puskesmas Lawang akan dipaparkan pada tabel 2 .

Tabel 2. Analaisis Pelaksanaan SOP Penyimpanan Berkas Rekam Medis

\begin{tabular}{|c|c|c|c|}
\hline \multirow[t]{2}{*}{ No } & \multirow[t]{2}{*}{ Uraian Prosedur } & \multicolumn{2}{|c|}{ Pelaksanaan } \\
\hline & & Sudah & Belum \\
\hline 1 & $\begin{array}{l}\text { Petugas mengambil do- } \\
\text { kumen rekam medis dari } \\
\text { petugas poli }\end{array}$ & $\checkmark$ & \\
\hline 2 & $\begin{array}{l}\text { Petugas mencatat dikumen } \\
\text { rekam medis yang keluar } \\
\text { pada lembar ekspedisi re- } \\
\text { kam medis }\end{array}$ & & $\checkmark$ \\
\hline 3 & $\begin{array}{l}\text { Petugas mengembalikan } \\
\text { rekam medis sesuai dengan } \\
\text { nomor urut indexnya }\end{array}$ & $\checkmark$ & \\
\hline & $\begin{array}{l}\text { Petugas mengambil tracer } \\
\text { ke dalam rak penyimpanan } \\
\text { rekam medis masing-mas- } \\
\text { ing }\end{array}$ & & $\checkmark$ \\
\hline
\end{tabular}

\begin{tabular}{|c|c|c|c|}
\hline \multirow[t]{2}{*}{ No } & \multirow[t]{2}{*}{ Uraian Prosedur } & \multicolumn{2}{|c|}{ Pelaksanaan } \\
\hline & & Sudah & Belum \\
\hline 4 & $\begin{array}{l}\text { Petugas mengurutkan rekam } \\
\text { medis sesuai dengan nomor } \\
\text { indexnya }\end{array}$ & $\checkmark$ & \\
\hline 5 & $\begin{array}{l}\text { Petugas merapikan susunan } \\
\text { rekam medis agar tetap rapi } \\
\text { dan benar }\end{array}$ & V & \\
\hline
\end{tabular}

Berdasarkan hasil observasi, wawancara dan dokumentasi di Puskesmas Lawang petugas 30\% belum melaksanakan SOP dengan efektif. Karena petugas tidak mencatat dokumen rekam medis yang keluar maupun berkas rekam medis yang dipinjam ke dalam buku ekspedisi dan buku peminjaman berkas rekam medis.

\section{Alur Penyimpanan Berkas Rekam Medis}

Berikut adalah bagan alur penyimpanan berkas rekam medis Puskesmas Lawang.

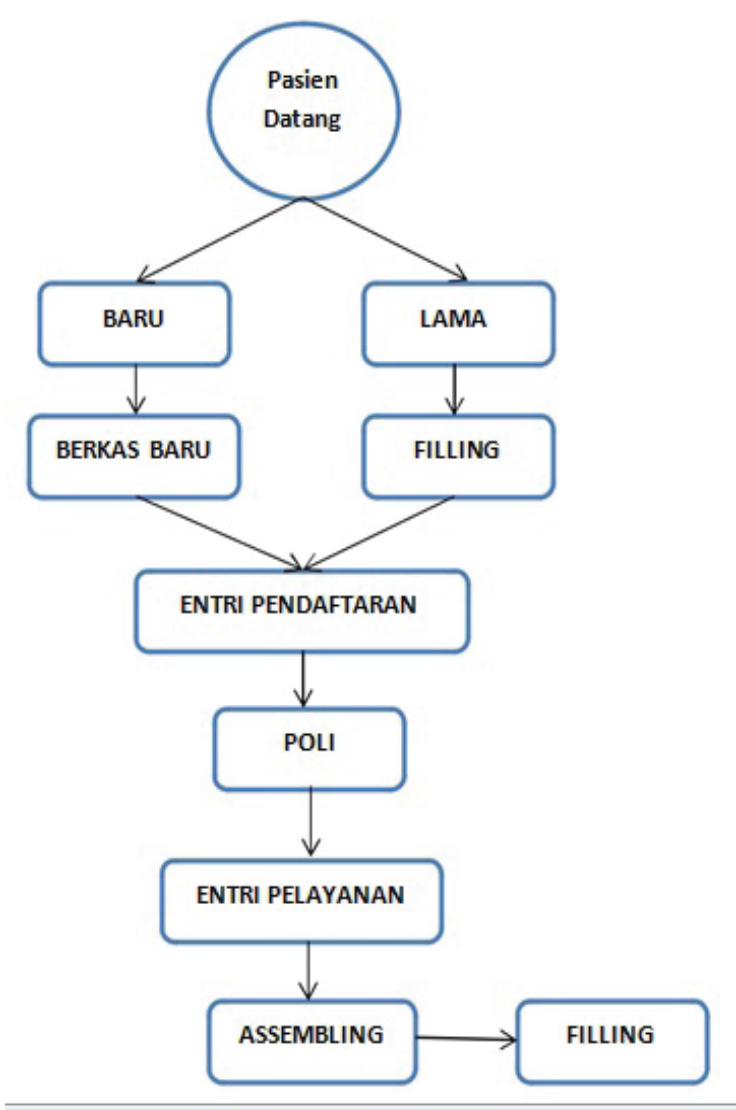

Gambar 1. Alur Penyimpanan Berkas Rekam Medis 
Berdasarkan hasil wawancara di Puskesmas Lawang belum terdapat alur berkas rekam medis secara tertulis. Dari bagan di atas dapat dijelaskan pasien datang menuju ke loket pendaftaran kemudian jika pasien baru maka pasien akan dibuatkan berkas baru, jika pasien lama maka akan diambilkan di ruang filling. Berkas dari filling di bawa ke pendaftaran untuk dilakukan pengentrian pendaftaran kemudian didistrubusikan ke poli.

Setelah berkas selesai digunakan maka perawat akan mengentri pelayanan medisnya dan petugas rekam medis mengambil kembali berkas rekam medis kemudian dilakukan proses assembling dan berkas dikembalikan ke filling kembali.

Pasien lama di Puskesmas Lawang dibagi menjadi 2 yaitu pasien umum dan pasien BPJS. Jika pasien tidak membawa kartu berobat maka petugas meminta fotocopi data diri pasien dan mengeceknya terlebih dahulu di aplikasi E-puskesmas. Kemudian petugas menulis nomor rekam medis pasien di nomor antrian dan mengambil berkas tersebut di ruang filling dengan cara menarik menonjol 2 berkas kemudian mengambil 1 berkas rekam medis dan qberkas rekam medis lain sebagai tanda jika berkas keluar. Berdasarkan hasil wawancara di Puskesmas Lawang tidak terdapat alur dokumen rekam medis secara tertulis dan tertempel.

\section{Sistem Penyimpanan Berkas Rekam Medis}

Tabel 3 Sistem Penyimpanan Berkas Rekam Medis

\begin{tabular}{|c|c|c|c|}
\hline \multirow[t]{2}{*}{ No } & \multirow[t]{2}{*}{ Kategori } & \multicolumn{2}{|l|}{ Uraian } \\
\hline & & $\begin{array}{l}\text { Rawat } \\
\text { Jalan }\end{array}$ & $\begin{array}{l}\text { Rawat } \\
\text { Inap }\end{array}$ \\
\hline 1 & $\begin{array}{l}\text { Sistem Penyim- } \\
\text { panan }\end{array}$ & Sentralisasi & Sentralisasi \\
\hline 2 & $\begin{array}{l}\text { Sistem Penjaja- } \\
\text { ran }\end{array}$ & $\begin{array}{l}\text { Straight } \\
\text { Numerical } \\
\text { Filling }\end{array}$ & $\begin{array}{l}\text { Straight } \\
\text { Numerical } \\
\text { Filling }\end{array}$ \\
\hline 3 & $\begin{array}{l}\text { SOP Penyim- } \\
\text { panan rekam } \\
\text { merdis }\end{array}$ & Ada & Ada \\
\hline
\end{tabular}

Hasil observasi dan wawancara di atas (Tabel 3) sistem penyimpanan berkas rekam medis menggunakan cara Sentralisasi. Sentralisasi adalah sistem penyimpanan dimana berkas pasien rawat jalan dan rawat inap disimpan pada 1 ruangan yang sama, sehingga memudahkan petugas dalam mencari berkas rekam medis rawat inap maupun rawat jalan.

Sistem Penjajarannya menggunakan straight numerical system yaitu dokumen rekam medis disimpan dalam rak secara berurutan sesuai dengan urutan nomor rekam medis pasien. Di Puskesmas Lawang terdapat SPO tertulis terkait pelaksanaan penyimpanan rekam medis yang mengatur tentang aturan atau langkah-langkah penyimpanan dokumen rekam medis, peminjaman dokumen rekam medis dan pendistribusian rekam medis.

\section{Pengambilan Berkas Rekam Medis}

Pengambilan berkas rekam medis tidak menggunakan tracer. Di bawah ini adalah gambar berkas rekam medis keluar tanpa tracer sebagai petunjuk berkas keluar.

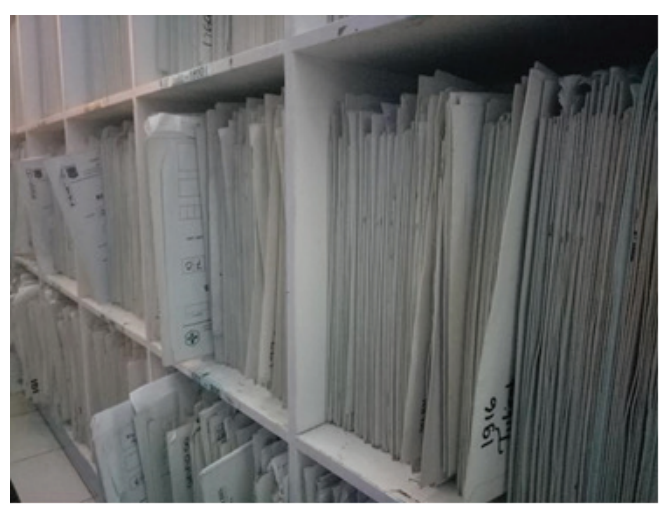

Gambar 2. Berkas Rekam Medis keluar tanpa tracer pada tahun 2018

Petugas $90 \%$ sudah mengembalikan rekam medis sesuai dengan urutan nomornya tetapi tidak menggunakan tracer saat berkas rekam medis keluar sampai berkas masuk/kembali ke ruang penyimpanan padahal tracer sudah ada. Petugas memilih menggunakan berkas yang berada dibelakang rekam medis keluar, sehingga jika berkas hilang atau belum kembali petugas kesulitan dalam melacaknya. Petugas sudah mengurutkan dan merapikan susunan rekam medis agar tetap rapi dan benar. 


\section{Ruang Penyimpanan Berkas Rekam Medis}

Berdasarkan observasi dan wawancara dapat disimpulkan dalam table 4 dibawah ini.

Tabel 4. Jarak Pendistribusian dokumen Rekam Medis

\begin{tabular}{llll}
\hline No & Ruang & Letak Ruang & Jarak \\
\hline $\mathbf{1}$ & Poli Umum 1 & Dalam Gedung & $\pm 4 \mathrm{~m}$ \\
$\mathbf{2}$ & Poli Umum 2 & Dalam Gedung & $\pm 8 \mathrm{~m}$ \\
$\mathbf{3}$ & Poli KIA & Dalam Gedung & $\pm 6 \mathrm{~m}$ \\
$\mathbf{4}$ & Poli Gigi & Dalam Gedung & $\pm 5 \mathrm{~m}$ \\
$\mathbf{5}$ & Poli TB & Luar Gedung & $\pm 18 \mathrm{~m}$ \\
$\mathbf{6}$ & UGD & Luar Gedung & $\pm 22 \mathrm{~m}$ \\
\hline
\end{tabular}

Jarak yang ditempuh petugas rekam medis dalam pendistribusian berkas rekam medis \pm 1 menit poli dalam ruangan dan \pm 3 menit untuk poli TB dan UGD (luar ruangan).

Ukuran ruang filling berkas rekam medis sangat kecil yaitu $2 \mathrm{~m} \times 2,5 \mathrm{~m}$ dengan berkas rekam medis sebanyak 29.200 berkas. Hal ini karena pada saat pembangunan ruang filling belum terdapat petugas yang sesuai dengan kualifilasinya sehingga pembangunan ruang filling dilakukan seadanya dengan memanfaatkan lahan yang ada. Kemudian Letak arsip SOP dan SK untuk rekam medis berada di atas meja pelayanan pendaftaran pasien yang terletak di sebelah kiri komputer 2 .

\section{Pembahasan}

\section{Kualifikasi Petugas Rekam Medis}

Faktor terpenting dari suatu pelaksanaan sistem untuk mencapai pelayanan kesehatan yang optimal adalah manusia. Dalam penyimpanan dokumen rekam medis sumber daya manusia adalah faktor yang sangat penting. Berdasarkan data dari identifikasi man secara kualitatif terdapat 4 petugas yaitu lulusan D3 Kebidanan sebanyak 1 orang, D3 RMIK sebanyak 1 orang dan 2 orang petugas lulusan SMA.

Menurut Mcllveen (2012) untuk menjalankan pekerjaan rekam medis diperlukan sumberdaya manusia yang memenuhi kompetensi perekam medis. Seorang profesi perekam medis merupakan lulusan dari program Diploma 3 pendidikan rekam medis dan informasi kesehatan.

Profesi perekam medis harus menguasai kompetensinya sebagai seorang perekam medis. Kompetensi pokok meliputi 5 hal, yaitu Klarifikasi \& kodifikasi Penyakit/Tindakan, Aspek Hukum Rekan Medis \& Etika Profesi, Manajemen Rekam Medis \& Informasi Kesehatan, Menjaga dan Meningkatkan Mutu Rekam Medis \& Informasi Kesehatan, Statistik Kesehatan. Sedangkan untuk kompetensi pendukung meliputi 2 hal, yaitu Kemitraan Kesehatan dan Manajemen Unit Kerja Rekam Medis.

Meskipun telah diberikan pelatihan, namun SDM lulusan SMA tetap saja tidak memiliki dasar pengetahuan terkait berkas rekam medis, hal ini akan berakibat pada kinerja petugas rekam medis yang cenderung berpeluang melakukan kesalahan saat bekerja. Wang, et al (2014) memaparkan bahwa pegawai rumah sakit yang tidak bekerja sesuai dengan bidang keilmuaanya akan menyebabkan banyak kesalaahan dalam bekerja. Hal ini dikarenakan bidang kesehatan sangat membutuhkan dasar teoritis dan praktis yang kompleks. Sehingga penanggung jawab pekerjaan tersebut harus orang yang memiliki kompetensi yang sesuai (Mcllveen, 2012).

\section{SOP Penyimpanan Rekam Medis}

Berdasarkan observasi dan wawancara yang dilakukan terdapat perbedaan antara SOP Penyimpanan berkas rekam medis dengan pelaksanaan penyimpanan. Sedangkan secara teori Standar Prosedur Operasional (SPO) adalah sistem yang disusun untuk memudahkan, merapihkan dan menertibkan pekerjaan. Sistem ini berisi urutan proses melakukan pekerjaan dari awal sampai akhir.

Sailendra, (2015:11) menyatakan "Standard Operating Procedure (SOP) merupakan panduan yang digunakan untuk memastikan kegiatan operasional organisasi atau perusahaan berjalan dengan lancar". Budihardjo (2014) menyatakan :"Standard Operating Procedure (SOP) adalah suatu perangkat lunak pengatur, yang mengatur tahapan suatu proses kerja atau prosedur kerja tertentu. Karena pelaksanaan penyimpanan berkas rekam medis di Puskesmas Lawang masih belum sesuai dengan SOP yang ditentukan, mengakibatkan pelayanan kesehatan menjadi kurang efektif. 
Ina Suhartina, Tri Murni, M, Riska Diana, P. Analisis Efektivitas SOP Pelaksanaan Penyimpanan ....

\section{Alur Penyimpanan Berkas Rekam Medis}

Alur penyimpanan berkas rekam medis Puskesmas lawang sudah baik. Hal ini sesuai dengan pendapat Hatta (2012) yang memaparkan kelengkapan proses penyimpanan berkas, mulai dari pendaftaran berkas sampai pada penyimpanan berkas. Hatta (2012) menjelaskan bahwa berkas rekam medis harus dikualifikasikan sesuai tipe tindakan dimana Puskesmas Lawang telah mengklasifikasikan berkas menjadi 2, yakni pasien rawat inap dan pasien rawat jalan.

\section{Sistem Penyimpanan Berkas Rekam Medis}

Berdasarkan Observasi di Puskesmas Lawang masih ditemukan berkas rekam medis 02-60-01 sampai dengan 02-92-00 yang masih belum menggunakan map. Sedangkan menurut Indradi (2014) berkas rekam medis berisi data individual yang bersifat rahasia, maka setiap lembar formulir berkas rekam medis harus dilindungi dengan cara dimasukan ke dalam folder atau map sehingga setiap folder berisi data dan informasi hasil pelayanan yang diperoleh pasien secara individu.

Untuk perlakuan penyimpanan berkas rekam medis berbeda dengan penyimpanan folder atau map perkantoran. Tujuan penyimpanan dokumen rekam medis adalah untuk mempermudah dan mempercepat ditemukan kembali berkas rekam medis yang disimpan dalam rak filling, mudah mengambil dari tempat penyimpanan, mudah pengembaliannya, melindungi berkas rekam medis dari bahaya pencurian, bahaya kerusakan fisik, kimiawi dan biologi.

\section{Pengambilan Berkas Rekam Medis}

Berdasarkan Hasil Observasi, wawancara dan dokumentasi di Puskesmas Lawang. Saat berkas rekam medis akan keluar tracer tidak digunakan dirawat jalan maupun rawat inap. Hal ini dikarenakan petugas yang ada sangat minim dan waktu pengambilan berkas lebih cepat menggunakan berkas lain sebagai alat petunjuk bahwa berkas rekam medis keluar. Dari gambar di bawah terlihat bahwa berkas rekam medis 00-16-70 digunakan sebagai alat petunjuk berkas rekam medis 00-16-71 yang keluar. Sedangkan menurut Widjaya (2014), outguide atau kartu petunjuk atau yang sering disebut dengan tracer adalah kartu yang digunakan untuk mengganti berkas rekam medis yang diambil untuk berbagai keperluan. Tracer berisi tentang tanggal peminjaman, nama peminjam, unit pengguna, serta keperluan peminjam. Kartu ini harus diisi sebelum rekam medis dipinjam sebagai pengganti rekam medis yang keluar dari rak penyimpanan.

Menurut (WHO, 2017) menggunakan petunjuk keluar atau tracer meningkatkan kerja instalasi rekam medis dan pengawasan rekam medis. petunjuk keluar atau tracer yaitu untuk memastikasn bahwa rekam medis setiap kali akan dipindahkan dari penyimpanan untuk tujuan apapun, harus diganti dengan tracer, yang menunjukkan dimana rekam medis telah dikirim. Tracer juga disebut outguide di banyak negara. Tracer atau outguide memungkinkan rekam medisuntuk ditelusuri bila tidak ada di penyimpanan.

\section{Ruang Penyimpanan Berkas Rekam Medis}

Almasyah (2011) yang menyatakan bahwa pada unsur material dokumen rekam medis tidak menggunakan map dan DRM, namun menggunakan kertas kuarto. Alat penyimpanan yang baik, penerangan yang baik, pengaturan suhu pemeliharaan ruangan, perhatian terhadap faktor keselamatan, bagi suatu kamar penyimpanan berkas sangat membantu memelihara dan mendorong kegairahan kerja dan produktivitas para pekerja, rak terbuka lebih dianjurkan pemakaiannya

Jarak antara dua buah rak untuk lalu lalang, dianjurkan selebar $90 \mathrm{~cm}$, jika menggunakan jari lima laci satu baris ruangan lowong didepannya harus $90 \mathrm{~cm}$ jika diletakkan saling berhadapan harus disediakan ruang lowong paling tidak $150 \mathrm{~cm}$. Untuk memungkinkan terbuka laci-laci tersebut lemari lima laci memang tampak lebih rapi dan berkas dapat terlindung dari debu dan kotoran dari luar, namun satu pemeliharaan kebersihan yang baik, akan memelihara berkas tetap rapi dalam hal penggunaan rak terbuka (DepKes RI, 2006).

\section{Simpulan}

Pelaksanaan SOP Sistem Penyimpanan berkas rekam medis tahun 2018 belum efektif: pengambilan yang tidak menggunakan petunjuk berkas keluar (Outguide), tidak terdapat alur dokumen rekam medis secara tertulis dan tertempel. 


\section{Ucapan Terima Kasih}

Pertama-tama, penulis ingin mengicapkan rasya syukur kepada Tuhan yang Maha Esa. Penulis juga mengucapkan banyak terimakasih kepada semua pihal yang telah banyak berkontribsi dalam penelitian ini. Sealin itu kepada pihak Puskesmas Lawang yang telah memberikan kesempatan pada penulis untuk melakukan penelitian.

\section{Daftar Pustaka}

Alamsyah, D. (2011). Manajemen Pelayanan Kesehatan. Yogyakarta:Nuha Medika.

Budihardjo, M. (2014). Panduan Praktis Menyusun SOP. Jakarta: Raih Asa Sukses.

Butt, M,. \& de Run, E. (2010). Private healthcare quality: applying a SERVQUAL model. Int $J$ Health Care Qual Assur. 23 (7) : 65-73.

Cresswell, John W. (2014). Research Design Qualitative, Quantitative, and Mixed Methods Approaches. SAGE Publications Ltd:Unite Kingdom.

Cresswell, John W. (2015). Penelitian Kualitatif dan Desain Riset:memilih diantara lima pendekatan. Yogyakarta:Pustaka Pelajar.

Denzin, N,. \& Lincoln, Y (eds.). 2011. Handbook of Qualitative Research. Terj. Dariyatno dkk. Yogyakarta: Pustaka Pelajar.

Depkes, RI. (2006). Pedoman Penyelenggaraan Dan Prosedur Rekam Medis Rumah Sakit Di Indonesi(Revisi II). Jakarta: Direktorat Jendral Bina Pelayanan Medik.

Hatta, G.R. (2012). Pedoman Manajemen Informasi Kesehatan di Sarana Pelayanan Kesehatan. Jakarta: Universitas Indonesia.
Indradi, R. (2014). Rekam Medis. Tangerang Selatan:Universitas Terbuka.

Ismainar, H. (2018). Manajemen Unit Kerja: UntukPerekam Medis dan Informasi Kesehatan Ilmu Kesehatan Masyarakat Keperawatan dan Kebidanan. Yogyakarta:Deepublish.

Mcllveen, P. (2012). A Longitudinal Study of The Experience of A Career Development Program For Rural School Students. Career Education and Higher Education. 3(1) : 11-14.

Murni, T., Suhartina, I., \& Fransiskus, W. (2018). Analisis Penggunaan Kembali Map Rekam Medis dalam Upaya Memperoleh Efisiensi Biaya di Siloam Hospitals Surabaya. Jkesvo.3(2): 53-61

Sailendra, A. (2015). Langkah-langkah Praktis Membuat SOP. Yogyakarta: Trans Idea Publishing.

Wang, Y., Chiang, M., \& Lee, Y. (2014). The relationships amongst the intern anxiety, internship outcomes, and career commitment of hospitality college students. Journal of Hospitality, Leisure, Sport and Tourism Education. 15 (4) : 86-93.

Widjaya, L. (2014). Modul 2B Sistem Rekam Medis dan Manajemen Informasi Kesehatan tentang Pengarsipan Rekam Medis. Jakarta: Universitas Indonesia.

World Health Organization. (2017). Medical Records Manual, A Guide for Developing Countries. Geneva: WHO Library Cataloguing in Publication Data. 